\title{
"Lo que pasa es que la política se ha puesto farandulera": justificaciones atenuantes de aserciones de opinión en el corpus PRESEEA de Santiago de Chile*
}

\author{
"Lo que pasa es que la política se ha puesto farandulera": \\ mitigating justifications in opinion assertions in the PRESEEA \\ corpus from Santiago, Chile
}
Silvana Guerrero González ${ }^{* *}$, Consuelo Gajardo Moller ${ }^{* * *}$, Javier González Riffo ${ }^{* * * *}$, Antonia Reyes O’Ryan ${ }^{* * * * *}$

\section{RESUMEN}

En esta investigación se indagó en el comportamiento pragmáPalabras clave: tico-discursivo de las estrategias retóricas que permiten justifiatenuación, car los actos de habla asertivos en el corpus del Proyecto para el Estudio Sociolingüístico del Español de España y de América de Santiago de Chile. Se describen tres estrategias que se emplean compromiso del hablante, imagen, justificaciones. para justificar en el español chileno: las justificaciones propiamente tales, las explicaciones y las comparaciones. Se revisa el funcionamiento pragmático-discursivo de los recursos lingüísticos disponibles para justificar en cada estrategia, esbozando una formalización de los mismos y, finalmente, se da cuenta de cómo operan dichas estrategias en relación con las funciones de la atenuación, en cuyo caso se pudo concluir que las estrategias en estudio operan como autoprotección para salvar la imagen propia y/o como prevención de posibles daños a la imagen del otro.

Este trabajo se enmarca en el proyecto de investigación "La atenuación lingüística en el español chileno: enfoque pragmalingüístico y sociopragmático" (ANID/Conicyt Fondecyt Regular 1200003).

** Chilena. Doctora en Lingüística. Académica de la Universidad de Chile, Santiago, Chile.siguerrero@u.uchile.cl

*** Chilena. Doctora en Lingüística. Académica de la Pontificia Universidad Católica de Chile, Santiago, Chile. cgajardom@uc.cl

**** Chileno. Estudiante de Doctorado en Lingüística. Pontificia Universidad Católica de Chile, Santiago, Chile.jdgonzalez@uc.cl

***** Chilena. Estudiante de Licenciatura en Lingüística y Literatura Hispánica Mención Lingüística. Universidad de Chile, Santiago, Chile. antonia.reyes.o@ug.uchile.cl 


\begin{abstract}
This study examined the pragmatic and discursive behavior of the rhetorical strategies that allow for justifying assertive speech acts in the Proyecto para el Estudio Sociolingüistico del Español de España y de América de Santiago de Chile corpus. Three strategies used for justifying in Chilean Spanish have described: justifications as such, explanations, and comparisons. This investigation revised the pragmatic and discursive function of the linguistic resources available for justifying each strategy and offers a systematization of said resources. Finally, it gives an account of how these strategies work with the functions of mitigation. In which case, this research concludes that the strategies under study function as a means for self-protection to safe the speaker's face and/or prevent potential threats to the hearer's face.
\end{abstract}

Keywords: face, justifications, mitigation, speaker's commitment. 


\section{Introducción}

La atenuación constituye un recurso retórico-comunicativo, originado por necesidades de imagen, que tiene como función mitigar o minimizar la intensidad de lo expresado y reducir lo que se calcula por los hablantes como amenazante o como menos exitoso en un determinado contexto (Briz y Albelda, 2013).

Con este supuesto se han estudiado y caracterizado diversos recursos de atenuación de forma independiente. Un recurso cuya caracterización no ha sido suficientemente tratada es la justificación. A este respecto, Albelda (2010) precisa que, en los actos asertivos, la estrategia primordial de la atenuación se dirige esencialmente a reducir el compromiso epistémico del hablante hacia la verdad que está expresando, a suavizar, o bien, relativizar la expresión de los juicios u opiniones del propio hablante, pues calcula que su imagen podría verse afectada. Para ilustrar la manera en que funciona la justificación atenuante como una estrategia pragmática, presentamos el siguiente ejemplo:

(1) E: o sea / usted es exigente con sus amigos / o sea / si ya tiene un amigo // I: es que yo creo que he tenido por eso / a lo mejor / he tenido una o dos amigas que sean de ese estilo / o sea de / a quien tú recurres / a quien tú le cuentas cosas / pero demás son personas más / personas igual conocidas con quien tú lo pasas bien y todo / claro / pero no de ir así / o sea / de contar cosas de / más allá de intimidades no /o sea / he sido como [de] pocos / en ese sentido / amigos amigos (SCHI_M22_055) ${ }^{1}$.

En el ejemplo citado podemos observar que los atenuantes funcionan de manera solidaria, es decir, no aparece un recurso de atenuación aisladamente, sino que se presentan en cadena. En este caso, el entrevistador realiza un comentario que podría poner en riesgo la imagen de la informante ("usted es exigente con sus amigos"), el que actúa como desencadenante de una justificación, de tal forma que ella comienza su intervención con "es que", cuyo empleo está asocia-

Todos los ejemplos son parte del corpus analizado. Se transcriben de manera ortográfica y al final de cada uno se codifica, entre paréntesis, la información relativa al informante. Para la lectura, debe considerarse que $\mathrm{E}$ = entrevistado e I = informante. Solo se analizan los actos de habla del informante: se usa cursiva y negrita para identificar los atenuantes aludidos, y solo cursiva para marcar el resto de los atenuantes. 
do al uso de la primera persona singular "yo" junto con un verbo con el que se muestra su punto de vista ("creo"), pero dejando la opción de incluir otros puntos de vista posibles. Así, la informante se autoprotege frente a su interlocutor, en el sentido de que no quiere parecer alguien "exigente" con sus amigos; de hecho, en su construcción discursiva hace la diferencia entre los amigos comunes y aquellos que denomina "amigos amigos", es decir, los amigos de verdad. Con esto también contribuye a prevenir algún posible conflicto, dado que el entrevistador podría no estar de acuerdo con lo que ella considera un amigo verdadero y/o con su forma de ver la amistad (de ahí que la considere exigente). Se observa, en paralelo, el uso de "a lo mejor", valoración epistémica que permite expresar lo señalado como una suposición que indica duda, y se incluye el uso de "como" para reducir la especificidad del contenido proposicional, volviéndolo más vago. De esta forma, la informante evade cierta responsabilidad respecto de lo dicho u opinado.

Siguiendo las bases teórico-metodológicas de la pragmalingüística, en esta investigación se estudiaron las estrategias para justificar los actos de habla asertivos en el corpus del Proyecto para el Estudio Sociolingüistico del Español de España y de América (PRESEEA) de Santiago de Chile. Para ello, desarrollamos una propuesta de sistematización de las estrategias que cumplen la función de atenuar justificando en la variedad chilena del español, revisamos el funcionamiento pragmático-discusivo de los recursos lingüísticos disponibles para justificar en cada estrategia $\mathrm{y}$, por último, indagamos en el funcionamiento de las estrategias y los recursos empleados para justificar según las funciones de la atenuación respecto de la imagen: autoprotección, prevención y reparación.

Esta investigación se justifica, en primer lugar, por el desequilibrio que existe en torno a los estudios referidos a la atenuación, ya que los existentes se instalan, en su mayoría, en la sociolingüística variacionista. En segunda instancia, se proporcionan nuevos detalles acerca de la construcción de los significados sociales implicados en las secuencias verbales y se contribuye a la reflexión en torno a cómo los hablantes construyen y negocian su identidad en la interacción, en especial, porque el fenómeno en estudio también permite revelar los posicionamientos ideológicos y las identidades que son más o menos aceptadas y consensuadas. 


\section{Marco teórico}

\subsection{La atenuación lingüística}

Los estudios acerca de la atenuación (o mitigación ${ }^{2}$ ) son múltiples. Albelda (2018c) simplifica las diversas propuestas existentes y sintetiza en cuatro aspectos las propiedades constitutivas de lo que se ha entendido por atenuación: reduce el impacto de los efectos no deseados en las imágenes de los interlocutores; reduce la precisión en el significado proposicional y/o hace vaga la proposición; reduce la fuerza ilocutiva del acto de habla; y reduce el compromiso del hablante con lo dicho y las obligaciones de los interlocutores. Por consiguiente, se postula que se trata de una categoría pragmática (mecanismo estratégico y táctico, dirigido a la efectividad y eficacia discursivas), de una estrategia (que atenúa en términos argumentativos, para lograr el acuerdo o la aceptación del otro) y de un mecanismo retórico (para convencer, persuadir y cuidar las relaciones sociales e interpersonales o evitar su menoscabo) (Briz y Albelda, 2013).

En el ámbito hispano existen múltiples investigaciones referentes a la atenuación lingüística (y paralingüística). Por mencionar algunas de las más relevantes, se puede señalar a Molina Martos (2005), Briz (2002, 2003, 2004, 2006, 2007, 2012), Briz y Estellés (2010), Cestero (2012a, 2012b, 2017), Albelda y Álvarez (2010), Albelda y Cestero (2011), Cestero y Albelda (2012), Briz y Albelda (2013), Samper (2013, 2017, 2018), Schneider (2013, 2017), Torres y Rodríguez (2016), Albelda y Mihatsch (2017), Albelda (2016, 2018a, 2018b, 2018c), Figueras (2018) y Rodríguez Alfano (2018). Dichos estudios empíricos no solo han propuesto una definición de lo que se entiende por atenuación, sino que además han desarrollado constructos metodológicos y analíticos que han permitido llevar a cabo una serie de trabajos de carácter descriptivo y/o contrastivos del funcionamiento de la atenuación en las distintas variedades del español. Para el caso del español de Chile se cuenta, entre otras, con las investigaciones empíricas de Puga (1997), cuyo estudio sobre la atenuación desde el punto de vista pragmático se perfila como pionero en Chile; Montecino (2003, 2004), quien se enfoca en la relación entre cortesía y atenuación, por

Atenuación, mitigación o hedges (cf. Briz y Albelda, 2013). 
un lado, e intensificación y discurso oral, por el otro; González Riffo y Guerrero González (2016, 2017, 2018) y González Riffo (2017, 2019), cuyos esfuerzos han estado centrados en presentar los resultados de sus análisis sobre la atenuación lingüística y paralingüística en el español de Chile actual. En suma, los estudios citados abordan la atenuación desde dos grandes paradigmas: el de la variación, cuya base es la sociolingüística, y el de los géneros discursivos, sustentado en las directrices teórico-metodológicas del análisis del discurso con un enfoque pragmático.

\subsubsection{Funciones de la atenuación, imagen y compromiso del hablante}

Los estudios en lengua española han relacionado la atenuación con tres funciones básicas: 1) autoprotección (salvaguarda el yo), esto es, el uso de atenuadores para evitar o reducir el compromiso del hablante con lo dicho o su repercusión y para salvar la imagen propia; 2) prevención (salvaguarda el yo y el tú), en cuyo caso se tiende a evitar las repercusiones de lo dicho o hecho e imponer la opinión propia, buscando acuerdo o justificando el desacuerdo; se previenen posibles daños a la imagen o problemas por invadir el territorio del otro; y 3) reparación, cuya función es mitigar o reparar una amenaza al interlocutor (Briz y Albelda, 2013) ${ }^{3}$. En este sentido, se entiende imagen como propone Figueras (2018) "la imagen constituye el sentido reclamado por la persona de valoración social favorable del yo en un contexto relacional" (p. 260); la imagen debe entenderse como un recurso de carácter identitario vulnerable, que puede amenazarse o realzarse en cualquier situación social. La imagen opera en la comunicación, pues se trata de un conglomerado de aspectos de identidad y relacionales. Estos planteamientos tienen su origen en Goffman (1967).

En otro orden de cosas, aunque siempre en relación con la imagen, entre los criterios que son empleados para reconocer la atenuación según Albelda (2018b) se hallan, en primer término, el significado difuso y la reducción de la fuerza ilocutiva y, como consecuencia de ellos, la

Debemos recordar que en la propuesta de Kerbrat-Orecchioni (1992) se habla de estrategias de autoprotección, prevención y compensación. 
indireccionalidad de los actos de habla atenuados, dado que se desajustan la intención del hablante y la expresión lingüística realizada; y, en segundo lugar, la función retórica y la función protectora de la imagen. A este respecto, las actividades de imagen se sintetizan en autoimagen (imagen propia positiva y neutralidad de la imagen del otro), cortesía (atención a la imagen del otro) y descortesía (ataque a la imagen del otro).

Finalmente, también en relación con el concepto de imagen, emerge la idea del compromiso del hablante. Albelda (2018c) se refiere a la responsabilidad del hablante hacia lo dicho. Este compromiso puede entenderse de diferentes formas vinculadas con la atenuación (o con la intensificación en un sentido gradual):

1) Compromiso basado en el juicio que la fiabilidad de la fuente merece al hablante.

2) Compromiso basado en el acuerdo y conformidad con el contenido de la evidencia.

3) Compromiso basado en el grado de certeza-probabilidad con el valor de verdad de la evidencia.

4) Compromiso basado en la implicación del hablante-conceptualizador en la construcción del enunciado.

Para efectos de las reflexiones que proponemos en esta investigación, se considerarán las formas (3) y (4) de manera diferenciada -siguiendo a Albelda (2018c)-, puesto que ambas se hallan íntimamente relacionadas con la intención de justificar lo dicho y, por tanto, se vinculan con la imagen del hablante.

\subsection{La justificación atenuante}

En su trabajo acerca de la conversación coloquial en español, Briz (2001) precisa que una forma de atenuar el discurso es por medio del ofrecimiento de rodeos justificativos. Si bien el autor no caracteriza mayormente dicho recurso, sí menciona que se puede suavizar la fuerza ilocutiva de las justificaciones por medio de expresiones como "es que" y "quería". 
En el estudio coordinado referido a la atenuación con los materiales del PRESEEA ${ }^{4}$ se propusieron 25 tipos diferentes de recursos lingüísticos y paralingüísticos de atenuación; entre ellos, se ubican las “justificaciones y excusas". Al respecto, Albelda y Cestero (2011) precisan que uno de los movimientos comunicativos y cognitivos generales que pueden llevar a cabo los atenuantes es justificar: "se puede justificar mediante cualquier mecanismo que apoye argumentativamente lo dicho y, a la vez, suponga una reducción del peso enunciativo del hablante" (p. 28). Entre las formas que adopta esta estrategia atenuante aparecen las justificaciones y excusas de lo dicho o del decir, el empleo de una comparación como forma de justificarse y el uso de marcadores discursivos que presentan consecución lógica.

En un estudio posterior acerca del español de Monterrey, Flores y Ramírez (2015) señalan que existen cuatro subestrategias destinadas a justificar en los actos de habla asertivos: las justificaciones, las explicaciones o excusas, las comparaciones y los marcadores discursivos que desempeñan la función de conectores lógicos. A nuestro juicio, en la propuesta citada no queda clara la diferencia entre justificaciones y explicaciones o excusas, pues sus definiciones se traslapan y, además, se presentan de manera tautológica. En este sentido, este trabajo intenta contribuir con una propuesta de sistematización que sea fácilmente replicable.

En otro orden, González Riffo y Guerrero González (2017) proponen el eje de veracidad para hablar de qué tan real es aquello que se dice en el contexto de las narraciones interaccionales. Las justificaciones se ubicarían en dicho eje y consistirían en intercalar explicaciones que justifiquen algún evento.

\section{Marco metodológico}

\subsection{El corpus y los informantes}

El corpus utilizado en esta investigación corresponde a 18 entrevistas semidirigidas del corpus del PRESEEA de Santiago de Chile. Tomando como base la Guía de Estudios de la Atenuación en los corpus PRESEEA,

\footnotetext{
4 Documento completo disponible en: http://preseea.linguas.net/ Metodolog\%C3\%ADa.aspx. Para ver el detalle del funcionamiento de estos recursos, se sugiere revisar los trabajos empíricos de Cestero y Albelda (2012) y el de Albelda (2018a).
} 
se seleccionaron 30 minutos de grabación (minutos 10 al 40) de cada entrevista, lo que constituye nueve horas de registro de discurso natural.

\subsection{Procedimientos analíticos}

Para llevar a cabo este estudio utilizamos como unidad de análisis el atenuante en un contexto interaccional concreto (Briz y Albelda, 2013), de modo que quedaron incluidos los siguientes tres segmentos analíticos: 1) el miembro del discurso afectado por la atenuación; 2) el miembro del discurso causante o desencadenante; y 3) la expresión atenuante concreta. Además, adoptamos la metodología de análisis propuesta en Cestero y Albelda (2012), Briz y Albelda (2013) y Albelda, Briz, Cestero, Kotwica y Villalba (2014) para identificar la estrategia de justificar con función atenuante. Para las subcategorías de la categoría en estudio, recurrimos a la propuesta de Flores y Ramírez (2015).

Un supuesto fundamental para llevar a cabo este estudio fue que la atenuación mediante justificaciones en los actos asertivos ocurre cuando está claramente comprometida alguna de las imágenes de los interlocutores. Para el investigador, entonces, debe resultar sencillo identificar si el mensaje transmitido supone una carga negativa (Albelda, 2010).

Se trató de un análisis inductivo que trabajó con tres pruebas: prueba de la ausencia, prueba de la conmutación y prueba de la solidaridad (Villalba, 2018). En este trabajo, hemos optado por usar estas tres pruebas de manera complementaria en la tarea de verificar el carácter atenuante de las expresiones revisadas.

\section{Presentación y discusión de los resultados}

En el estudio preliminar de Guerrero (en prensa) destinado a describir el fenómeno de la atenuación en el corpus del PRESEEA de Santiago de Chile en las dimensiones lingüística, pragmático-discursiva y social, se identificaron 304 de 1.731 casos en los que los hablantes utilizaban el recurso de justificaciones y excusas (Albelda y Cestero, 2011) para atenuar. En este estudio, se tomaron los 304 casos observados y se analizaron cualitativamente en el sentido que se ha indicado más arriba.

De acuerdo con los objetivos propuestos, la presentación de resultados se dividió en tres apartados: el primero presenta, en términos generales, la propuesta de estrategias utilizadas para justificar en los 
actos de habla asertivos; el segundo está destinado a exponer los resultados -de forma detallada y debidamente ejemplificada- de la revisión de los recursos lingüísticos disponibles para justificar en cada tipo de estrategia empleada en el corpus PRESEEA de Santiago de Chile; y, el tercero da cuenta de su operación en relación con las funciones de la atenuación (autoprotección, prevención y reparación).

\subsection{Estrategias para justificar en actos de habla asertivos}

En el presente estudio entendemos que existen dos tipos de actos asertivos: los de opinión y los de información. En los primeros, la imagen del hablante está más comprometida, por tanto, se espera mayor actividad atenuadora. En los segundos, el hablante solo describe un estado de cosas, sin realizar juicios o valoraciones, de modo que debiese haber menos atenuación (Albelda et al., 2014). En esta investigación trabajamos con aquellos actos asertivos en donde se exprese una opinión, pues en ellos la imagen del hablante está más comprometida al formularse juicios y valoraciones y, por tanto, se espera mayor actividad atenuadora. Con esta definición operacional -y a partir de la revisión de la propuesta original de la estrategia de atenuación denominada 'justificar' en Albelda y Cestero (2011) para el habla de Madrid y revisada en Flores y Ramírez (2015) para el español de Monterrey-, en esta investigación se han podido definir las siguientes estrategias asociadas con la idea de justificar los actos de habla asertivos en la variedad chilena del español:

a. Justificaciones: mediante esta estrategia el hablante ofrece razones que considera convincentes para probar algo. Se trata de razones que provienen de la propia experiencia del hablante, quien se justifica para apoyar argumentativamente lo dicho y quitarse toda o parte de su responsabilidad. Dado que corresponde a motivos centrados en el "yo", en el contexto interaccional concreto será esperable encontrar más comúnmente el uso de "yo", “a mí", “me” y otras personas gramaticales junto con verbos modales como "creer". Así, las justificaciones proporcionadas están destinadas fundamentalmente a autoproteger la imagen propia, puesto que concierne a temáticas conflictivas o de respuestas negativas, las que actúan como desencadenantes del atenuante. Para justificar la aserción se presenta primero la conclusión y luego los argumentos. 
b. Explicaciones: esta estrategia permite que el hablante dé a conocer, declare o manifieste la causa o motivo de algo, de manera que aclara lo dicho. Se trata de explicaciones destinadas a atenuar juicios u opiniones respecto de temas controversiales. Con las explicaciones no solo se autoprotege la imagen propia, sino que además se previene un posible conflicto, dada la naturaleza del desencadenante, el que puede estar contenido en la pregunta realizada por el entrevistador o en el juicio al que incita la pregunta. A diferencia de las justificaciones, en las explicaciones los argumentos provienen más comúnmente del mundo externo (y no se centran en el yo de manera exclusiva) y, por ello, será esperable el empleo de recursos de expresión de duda como "no sé", "quizás", "en realidad" u otros que colaboren solidariamente en la atenuación. En este caso, se presentan primero los argumentos y luego la conclusión.

c. Comparaciones: la comparación consiste en una estrategia en la que el hablante ofrece ejemplos de su propia experiencia o del mundo externo para quitarse toda o parte de la responsabilidad de lo dicho. En este caso, se fija la atención en dos o más objetos o situaciones para mostrar sus relaciones, diferencias o semejanzas.

La propuesta esbozada puede concretarse en una escala de compromiso del hablante, como muestra el siguiente esquema.

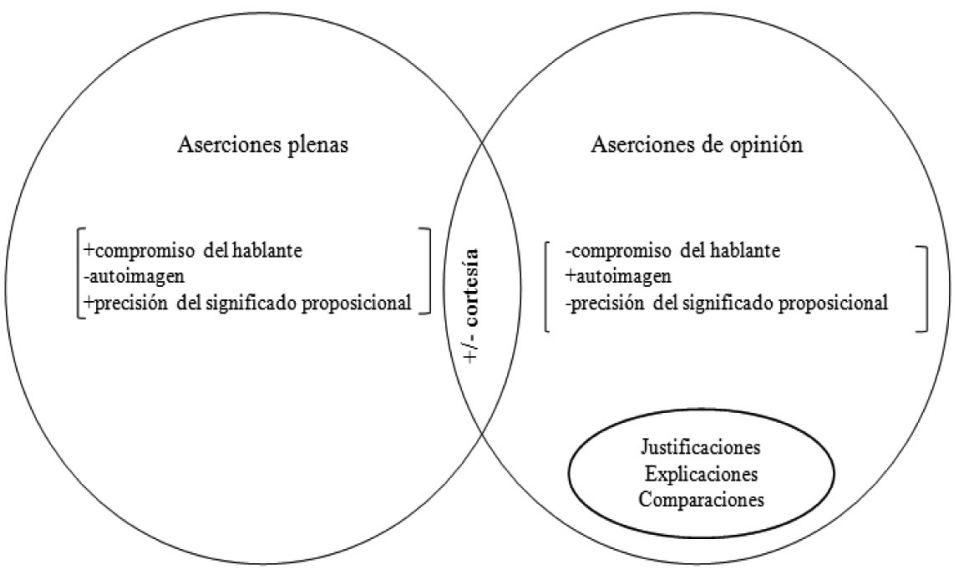

Esquema 1. Relación entre estrategias para justificar, imagen y compromiso del hablante.

Fuente: Elaboración propia. 
En el esquema precedente queda ilustrado el funcionamiento de las estrategias descritas para justificar los actos de habla asertivos: mientras menos responsabilidad o compromiso con lo dicho, se protege más la propia imagen, puesto que el significado proposicional es menos preciso, y mientras más responsabilidad o compromiso con lo dicho, el hablante protege menos su propia imagen (atenúa menos el acto asertivo, convirtiéndolo en un asertivo pleno) y expone el significado proposicional de manera más precisa. En ambos casos media la cortesía, en tanto principio pragmático y estrategia de las actividades de imagen que se orienta hacia el equilibrio social (Briz, 2004), ya que el hablante puede ser cortés o neutro con la imagen del interlocutor. Al emplear recursos lingüísticos que permiten realizar justificaciones, explicaciones y/o comparaciones se alcanza el grado máximo de ausencia de compromiso con lo dicho, puesto que se ofrecen razones internas o externas que actúan como recursos que el hablante evalúa como facilitadores en la tarea de reducir el compromiso epistémico (lo que incrementa la protección de la imagen propia) hacia la verdad que está expresando, o bien, suavizar su expresión de los juicios u opiniones cuando se trata de temáticas controversiales que suponen una carga negativa.

\subsection{Recursos lingüísticos disponibles para justificar en actos de habla asertivos}

De manera concreta, los recursos lingüísticos registrados en el análisis del corpus son los que se exponen a continuación.

\subsubsection{Justificaciones}

Como se adelantó, las justificaciones permiten al hablante apoyar argumentativamente lo dicho y quitarse toda o parte de su responsabilidad, y se introducen fundamentalmente a través de recursos lingüísticos como porque, que, lo que pasa es que y es que. El uso de estos recursos permite que el locutor exponga justificaciones que considera convincentes respecto de lo dicho. Los ejemplos (2) y (3) ilustran la construcción discursiva de esta estrategia.

(2) E: ya / oye y / de acuerdo a tu experiencia de vida / eeh / tú ¿cómo opinas que tratan / que se trata a los / a los viejitos ahora? // I: ¡como las huevas po! / yo pienso que tratan / por el mi <sic $>$ por 
ejemplo // E: porque antes los respetaban más ¿cierto? // I: claro / al menos yo / yo no estoy de acuerdo de las familias esas que van a a dejar a las abuelitas a los / o a los abuelos a los hogares de ancianos / porque ellos lo dieron todo por uno / yo / al menos yo con tu mamá / con mi mami yo no lo haría / si yo viera que mi mamá está así mal yo me la traería / yo la cuidaría hasta el último día de su vida / pero yo no lo haría / eeh / me carga esa huevada / no comparto esa idea de que vayan a tirar a los ancianos / porque ellos lo dieron todo por uno (SCHI_M21_019).

(3) E: y itú crees que las personas que van al gimnasio van solo a mejorar su estado físico / o van a conocer gente igual? // I: mira / más que nada yo iba a mejorar el estado físico / conocí gente / que yo soy bien amistoso / entonces me gusta conocer harta gente / pero aparte de eso por la salud de uno también (SCHI_H12_037).

En el caso (2), la informante está argumentando acerca de las razones de por qué no está de acuerdo con el trato que reciben las personas de la tercera edad. El desencadenante es la postura que explicita el entrevistador al comparar lo que ocurría antes con lo que sucede ahora ("porque antes los respetaban más ¿cierto?"). Puesto que la informante tiene una opinión negativa acerca de la sociedad chilena actual, justifica con su propia experiencia el hecho de que no incurriría en un acto como dejar a su madre en un hogar de ancianos; se complementa la justificación con el empleo de "al menos" y con el salto permanente de la primera persona "yo" ${ }^{5}$ explícita al impersonal "uno", que tiende a generalizar aquello que se dice y que, por tanto, le quita responsabilidad sobre lo dicho.

En (3) se genera una situación similar: la pregunta directa desencadena el uso de los atenuantes, puesto que ya carga con un juicio o con contenido enjuiciable. Para no imponerse, el hablante justifica su asistencia al gimnasio por asuntos físicos y de salud, y presenta como algo secundario el hecho de que, por ser amistoso, podía conocer gente. En este caso, el uso de la partícula concesiva "pero"

González Riffo y Guerrero González (2017) señalan que el uso explícito de yo se relaciona con posicionarse en el discurso e implica hacerse presente en el propio discurso. Para estos autores, el acto se posicionarse se ubica en lo que denominan el eje de certeza (38). 
permite introducir una contraexpectativa que anula la proposición anterior y avala el argumento a favor de la salud. En este ejemplo también se observa que el informante se posiciona con la expresión del sujeto explícito ("yo") y termina con el impersonal "uno". Su justificación es todavía más evidente cuando se incluye el uso de "que" en conjunto con el introductor "mira", que funciona como marcador discursivo con función atenuante y un recurso de modificación morfológica externa "más que nada", que agudiza el foco de lo que declara el hablante. En ambos casos, como vemos, los atenuantes funcionan de manera solidaria, es decir, no es solo el empleo de "porque" y "que" lo que valida la justificación, sino que también el contexto interaccional concreto.

En un segundo orden de cosas relacionadas con las justificaciones, resulta muy interesante que se generen casos donde se presenta la combinación porque + marcador discursivo, como queda ejemplificado en (4).

(4) E: em ya / y tus papás ¿cómo suelen divertirse? // I: mis papás // mi papá es súper fiestero / a mi papá le gusta salir / él sale de repente / él sale por ahí con la familia / con los hermanos sale ¿cachái? // mi mamá no // mi mamá su máxima diversión / lo que más le encanta a ella es estar durmiendo todo el día // porque igual / como ella sufre más por las enfermedades del cuerpo / y hace todas las cosas en la casa entonces anda siempre cansada // no es que ella pase durmiendo sino que lo que ella quiere es dormir más ¿cachái? (SCHI_M12_043).

En (4), el desencadenante es el juicio de la informante ("lo que más le encanta a ella es estar durmiendo todo el día”), quien realiza una comparación: puesto que su padre sale con frecuencia, debe justificar la actitud de su madre. Para esto, en lugar de usar solo "porque", agrega el marcador discursivo "igual", lo que le permite atenuar su juicio previo. Al eliminar la partícula "igual”, la fuerza ilocutiva del acto de habla se incrementa automáticamente. En este ejemplo es interesante que la informante, al usar el atenuante, no se autoprotege, sino que protege la imagen de su madre: ya ha señalado que a ella "le encanta dormir todo el día", lo que puede interpretarse como algo negativo de su personalidad; por ello justifica su actuar como un efecto de su enfermedad. 
Un tercer aspecto interesante para el caso de las justificaciones es que también se pueden realizar mediante la negación, como se aprecia en el ejemplo que sigue:

(5) E: ya / oye / en tu experiencia personal / ¿encuentras que el clima en Santiago ha cambiado? / que el / el tiempo no sé / que llueve más / ponle / que hace más calor / menos frío / no sé // I: / no creo / o sea sí cambia el ti / el clima / porque puta / de / no es porque / el cambio / el calentamiento global ni nada / toda / de todo eso / pero el clima va cambiando / de / de / de los dinosaurios huevón que era más caliente hasta el día / eh va cambiando la época del hielo / la era del hielo / todo eso / pero yo creo que cuando éramos chicos nosotros / estábamos a pata pelada y / con el short y la polera / cachái / pero ahora estamos con las chalas y con pantalón y la polera corta / y / somos nosotros los que estamos viejos (SCHI_H11_001).

La negación permite que la secuencia discursiva completa actúe como una construcción concesiva: se emplea "no es porque... pero...."

Otra forma de justificar lo dicho es la que se lleva a cabo a través del empleo de recursos como lo que pasa (es que):

(6) E: ¿y han entrado alguna vez a robar a la casa? // I: sí / yo estaba trabajando [...] claro que estuvieron ahí / que gracias a la / a la vecina de al frente fue porque cuanto se llama / es que después parece que llegaron fueron los carabineros / estuvieron revisando y ellos estaban tapados atrás / lo que pasa es que nunca hubo un cierre atrás / solamente eran maderas que estaban así en / así en la parte de ¿cuánto se llama? de de cerrar los / los sitios / nada más que eso / entonces por ahí se podrían haber fondeado // y ahí estaban también yo creo (SCHI_H22_049).

En casos como el citado, el hablante justifica su opinión en torno a los asaltos. El informante emplea su propia experiencia para comparar dos barrios santiaguinos, junto con la inclusión de datos que señala que provienen de fuentes externas. Los atenuantes aquí funcionan de la misma forma que porque, explicados anteriormente.

El empleo de causativos constituye otra forma de justificar los actos de habla asertivos. En este caso, se exige que los hablantes estén muy conscientes del discurso que están profiriendo, puesto que la conexión 
entre la conclusión lógica y el segmento discursivo desencadenante del empleo del causativo atenuante, debe contribuir a facilitar la inferencia del interlocutor. En el corpus del español chileno se ha registrado el uso de ya que:

(7) I: bueno durante la Navidad / se prepara un asadito / con papitas mayo / y una ensalada // E: y para usted / ¿cómo sería una celebración / ideal / de la Navidad? // I: bueno / una celebración ideal / sería con harta paz / y / estar con mis seres queridos // E: iy qué prefiere / el dieciocho / la Navidad / o le da lo mismo? // I: a mí me da lo mismo / las fiestas / no / no soy muy adicta a las fiestas / pero la Navidad por los niños / que ya que creen en / el viejito pascuero todavía (SCHI_M31_031).

Finalmente, se observa el empleo de algunas locuciones adverbiales que, en conjunto con otros atenuantes (por ejemplo "porque" y "por eso"), justifican la aserción. Se trata de expresiones como de repente y $a$ lo mejor, que en el español chileno tienen, entre otras funciones, la de atenuar el acto de justificar, al ser valoraciones epistémicas débiles del contenido proposicional. Los ejemplos que siguen refuerzan la idea de que los atenuantes que justifican disminuyen la fuerza argumentativa del acto de habla en el que se insertan.

(8) E: ya / a ¿y dejan a todos los maridos en las casas y se juntan las mujeres no más? // I: sí // sí / una vez fuimos a un pub también // no / pero la pasamos bien / súper entretenido / o sea / es agradable sí juntarse / porque de repente ha pasado que no nos juntamos un mes /y de repente / oye ¿qué pasa que no nos juntamos? (SCHI_ M22_055).

(9) I: es que yo creo que he tenido por eso / a lo mejor / he tenido una o dos amigas que sean de ese estilo / o sea de / a quien tú recurres / a quien tú le cuentas cosas / pero demás son personas más / personas igual conocidas con quien tú lo pasas bien y todo / claro / pero no de ir así o sea de contar cosas de / más allá de intimidades no (SCHI_M22_055)

En (8) y (9) el sentido de "de repente" y "a lo mejor" expresa una duda que posibilita la justificación. En (8), de hecho, podría eliminarse "porque", dado que es de repente la partícula que le permite al informante no imponer su opinión o atenuar su compromiso, disminu- 
yendo la fuerza argumentativa de lo expresado (Briz, Pons y Portolés, 2008). Además, su empleo debilita el argumento, porque implica una baja factibilidad del contenido proposicional del enunciado (Rojas, 2008). En (9) "a lo mejor" se presenta como una suposición que expresa la duda ante lo señalado; de esa manera la informante evade cierta responsabilidad sobre lo dicho (Briz et al., 2008). También en este ejemplo podría eliminarse "es que" y el contenido de lo dicho queda igualmente justificado. En ambos casos $x$ modalizador permite expresar duda.

\subsubsection{Explicaciones}

Las explicaciones permiten que el hablante dé a conocer o manifieste la causa o motivo de algo. Lo que se busca es explicar para atenuar juicios u opiniones respecto de temas controversiales. En este caso, se exponen las explicaciones y estas derivan en un juicio final emanado de ellas. Se llevan a cabo a través de por eso (que), como muestran los ejemplos que siguen.

(10) E: ya ¿cuál crees que es la razón por la cual los jóvenes de hoy optan por no casarse / y forman familias tardíamente? // I: yo creo que también / de nuevo es por una como una costumbre local // eeh o quizás / no sé yo creo que es producto de tantos hogares desarmados que / que al final la mayoría de las personas no invierten el tiempo quizás o los costos en en casarse y prefieren estar en algo más informal / la sociedad está apuntando a a un comportamiento mucho más individualista / sobre todo en la tecnología es a veces tiende a aislar a las personas quizás más que comunicarlas o sea el contacto humano se está reduciendo drásticamente / ahora todas las comunicaciones son por computador por correo electrónico / claro $o$ sea si un teléfono era impersonal ahora hablar por Messenger o servicio de mensajería cualquiera es es peor todavía / entonces las personas están tendiendo a ese individualismo a a vivir solo a a tener lazos quizás más informales / por eso yo creo que / en realidad pocas personas se interesan en formar una familia / más sobre todo la gente joven que no sé po (SCHI_H13_073).

(11) I: sí // porque el alcalde que es el señor X que fue reelegido otra vez como la quinta vez que es reelegido / se nota que trabaja bien porque está todo limpio / las calles limpiecitas // parques bonitos 
con fuente los semáforos donde corresponden // no hay hoyos en la calle // se nota que el hombre trabaja / se preocupa / por eso que fue reelegido como por cuarta quinta vez (SCHI_H33_097).

En los ejemplos (10) y (11) se pueden apreciar desencadenantes correspondientes a juicios acerca de temas altamente debatibles -el matrimonio joven y la política-. En ambos casos, los hablantes tienden a incluir argumentos antes de llegar a una conclusión: presentan argumentos $x 1, x 2$, xn "por eso (que)" $y$. En estos casos, además, los contextos interaccionales concretos presentan el uso de varios atenuantes que operan de manera solidaria y, por último, en los ejemplos, luego de "por eso" se introduce el efecto o consecuencia. La suma de argumentos permite justificar lo que los hablantes dicen; son por tanto la causa de lo dicho y no solo permiten atenuar opiniones, sino que dan la posibilidad de reducir el compromiso del hablante hacia lo dicho.

\subsubsection{Comparaciones}

Las comparaciones que permiten justificar lo dicho se instancian a través de la utilización de es como (que).

(12) I: la playa / no / mira / aparte que me baño poco / me gusta ir a tomar sol nomás / pero para el campo es otra cosa / es / no hay tanta bulla // es más natural y nunca tampoco había ido tantas veces al campo // ahora voy más cuando el X está un poco más grande / ahí me me he entretenido porque hay cosas más novedosas que en la playa / en la playa es ya es es como que estar aquí en Santiago / y ves peleas / la gente en general / es penca también la playa / pero para ir a distraerse un poco es bueno (SCHI_H22_049).

(13) E: ¿cuál es la diferencia entonces usted cree que / hay entre los amigos que se tienen de adulto // a los que se tienen cuando uno es chico cuando es niño? // I: jahh! que / es que mire es que cuando es chico uno / lleva otra otra ilusión es distinto / es como una ilusión es como un es como quien dice una amiguita / yo la conozco con mi amiguita / juego con mi amiguita / esto chiquitita de colegio es eso es ese es una amistad / y adultos es distinto (SCHI_M32_067).

En el ejemplo (12) el hablante compara la playa con el campo, equiparando a la primera con la vida en la ciudad y en (13) en tanto se están 
comparando diferentes etapas vitales. En ambos casos se emplea "es como (que)" para atenuar y no imponer la opinión propia: se autoprotege la imagen propia al poner casos concretos que permiten comparar para justificar la opinión y también para volver la proposición más vaga; se previene así un posible conflicto, puesto que se trata de temas debatibles.

La síntesis del funcionamiento de los recursos disponibles para atenuar en las aserciones es la siguiente:

a. Justificaciones: conclusión y (negación) porque / que / lo que pasa es (que) / es que / ya que (+ marcador discursivo) $x 1, x 2$, $x \mathrm{n}$ argumentos.

b. Explicaciones: argumentos $x 1, x 2, x \mathrm{n}$ por eso (que) conclusión $y$.

c. Comparaciones: $x=y$.

\subsection{Funciones de las estrategias para justificar en actos de habla asertivos}

Las funciones que cumplen las estrategias descritas en los apartados anteriores y explicadas en detalle en el contexto de los actos de habla asertivos en el corpus PRESEEA de Santiago de Chile, dicen relación con el empleo de formas de lenguaje difuso, con la reducción de la fuerza ilocutiva de los actos de habla atenuados y con su indireccionalidad. Justificar se constituye en un tipo de estrategia retórica que se genera cuando los hablantes calculan que su propia imagen o la de otro podría(n) verse afectada(s) por lo dicho. Consideremos el ejemplo (1), citado nuevamente aquí como (14), pero con más contexto:

(14) E: ¿qué es para usted tener un buen amigo? / ¿qué considera usted? // I: tener una buena amiga / tener un buen amigo / a ver / alguien en que tú puedas así como no sé po poder confiar / contarle cosas / pasarlo bien / entretenerse / disfrutar de cosas así / no sé po / tanto las cosas alegres como las cosas malas / tener alguien que / no sé po / que tú sientas que tú puedes contar con esa persona / y para eso son como muy pocas las personas // E: o sea / usted es exigente con sus amigos / o sea / si ya tiene un amigo // I: es que yo creo que he tenido por eso / a lo mejor / he tenido una o dos amigas que sean de ese estilo / o sea de / a quien tú recurres / a quien tú le cuentas cosas / pero demás son personas más / perso- 
nas igual conocidas con quien tú lo pasas bien y todo / claro / pero no de ir así / o sea / de contar cosas de / más allá de intimidades no /o sea / he sido como [de] pocos / en ese sentido / amigos amigos (SCHI_M22_055).

La intención detrás de la aseveración del entrevistador -“usted es exigente con sus amigos"- es que la informante construya un discurso que le permita justificar la diferencia que ha planteado antes entre lo que considera un amigo común y lo que valora como un verdadero amigo. En este sentido, se produce la indireccionalidad discursiva, ya que hay un desajuste entre la intención comunicativa de la informante y las expresiones lingüísticas empleadas: ella tiene clara la diferencia, pues ha iniciado su discurso con el atenuante "a ver" y utiliza permanentemente "tú" no con la intención de aludir a su interlocutor, sino que se trata de un uso generalizador. La informante justifica la diferencia expuesta para autoprotegerse y no ser considerada una amiga "exigente" mediante el uso de recursos lingüísticos como "es que" y "a lo mejor". Una situación similar se registra en (15):

(15) E: ya / en su opinión ¿cómo se explica / el desinterés de los jóvenes por la política? // I: lo que pasa es que la política se ha puesto farandulera también / así que yo creo también que por ahí puede ir un poco / y y a los políticos son los que menos le creen y uno lo puede ver / los políticos pasan todo el día en Santiago y no están nunca en su lugar de trabajo / así que creo que son contados / así que los jóvenes e incluso yo no estoy inscrito en los registros electorales (SCHI_H21_013).

En este caso el informante comienza atenuando mediante una explicación. Su postura ante el escenario político del país es negativa, por lo tanto, frente a una pregunta concreta, su enunciado reactivo se inicia con el atenuante "lo que pasa es que". Se incluye otra forma de justificar su postura correspondiente al consecutivo "así que". Sumado a esto, se halla el uso de otros atenuantes: "yo creo", donde se explicita la persona del hablante $-1^{\text {ra }}$ persona del singular "yo"-, y con ello se acota la opinión a la persona que habla, pero seguida de un verbo modal que expresa duda o incertidumbre -"creer"-. Esta estrategia retórica aparece modificada hacia el final de la intervención, donde se elide la persona para señalar solo "creo que". En ambos casos, el hablante expresa cierta inseguridad respecto de lo dicho, lo que además se com- 
plementa con la inclusión de "por ahí puede ir un poco". El uso de "un poco" actúa como un minimizador que modifica el sentido del enunciado en su totalidad. Por último, el informante incluye en su respuesta elementos que le permiten desfocalizar: se impersonaliza el sujeto del acto de habla con "uno" en lugar de "yo". Se trata de una intervención donde se produce una evolución en términos de posicionamiento, ya que el hablante va del lenguaje menos difuso al más difuso, con lo que consigue una reducción de la fuerza ilocutiva del acto de habla. En consecuencia, no solo se autoprotege, sino que también previene un posible daño al interlocutor.

Con los ejemplos anteriores, queda demostrado que el acto de justificar, independientemente de la estrategia empleada y los recursos lingüísticos desplegados, se relaciona con dos de las tres funciones de la atenuación: autoprotección y prevención, como se ilustra en el Esquema 2.

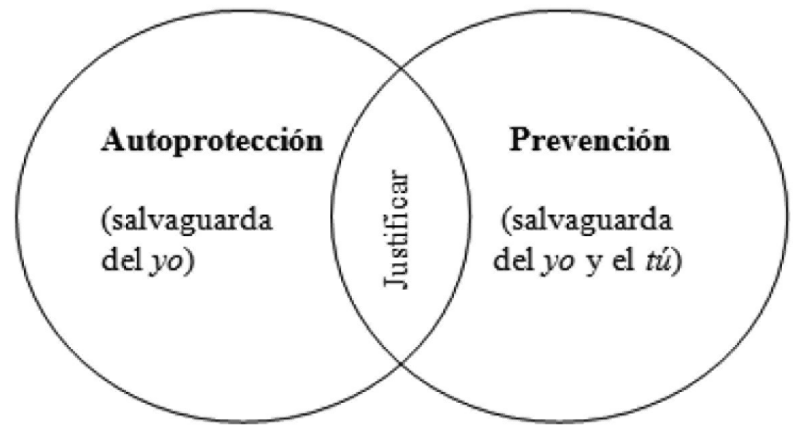

Esquema 2. Relación entre la acción de justificar y las funciones de la atenuación.

Fuente: Elaboración propia.

En el esquema precedente se hace explícita la doble función de la acción de justificar: por un lado, se trata de una estrategia retórica que minimiza el compromiso del hablante al presentar un contenido proposicional menos preciso, configurándose como una forma de autoimagen y, por otro, consiste en un recurso de cortesía del hablante y de su interlocutor, donde se toman los resguardos para evitar las repercusiones de lo dicho e imponer la opinión propia. Así, se previenen posibles daños a la imagen o problemas por invadir el territorio del otro. Se configura así 
una identidad donde se intenta mantener la relación en la interacción social y el yo se posiciona desde una doble vertiente: un yo independiente, donde el individuo comporta un repertorio de sentimientos, emociones y motivaciones, y un yo interdependiente, donde se refuerza la conectividad relacional (Figueras, 2018). Puesto que las aserciones son situaciones conflictivas, el yo sería el factor más influyente en el manejo de este tipo de interacción y el estilo discursivo para manejar el conflicto interpersonal correspondería a "integrar", entendido como un estilo que implica alta preocupación por el yo y por el otro (Figueras, 2018, p. 263). Por siguiente, la imagen se entiende como un recurso identitario vulnerable, dinámico y flexible, que puede amenazarse o realzarse en la situación comunicativa. En este sentido, la justificación de la aserción, sea mediante justificaciones propiamente tales, explicaciones o comparaciones, es un fenómeno que revela ciertos posicionamientos ideológicos, en el sentido de que relativiza la expresión de juicios u opiniones no solo para no invadir el territorio del otro, sino también para no atacar su imagen y para cuidar la propia cuando se manifiesta desacuerdo respecto de un desencadenante controversial. Se configura así una identidad solidaria y empática en la medida en que, aun cuando se tiene certeza de lo dicho, se elabora una práctica discursiva que manifiesta la reducción del compromiso epistémico.

\section{Conclusiones}

Los hallazgos de esta investigación se sintetizan de la siguiente manera:

En primer lugar, la atenuación de las aserciones efectuada mediante la acción de justificar se configura como una categoría pragmática, una estrategia y de un mecanismo retórico destinado a cuidar las relaciones sociales e interpersonales o evitar su menoscabo. Su funcionamiento reveló la existencia de tres estrategias que permiten justificar en el español chileno: las justificaciones propiamente tales, las explicaciones y las comparaciones.

En segundo término, cada una de las estrategias se configura según el uso de ciertos recursos lingüísticos, los cuales no operan de manera aislada, sino que se despliegan de forma solidaria en el acto de habla o, en otras palabras, suele haber presencia de más mecanismos atenuantes en el segmento que se está analizando. En este sentido, el acto de justificar-como cualquier acto de habla que implique la presencia de 
atenuantes- debe estudiarse en el contexto de la práctica discursiva en donde se genera.

En tercer lugar, esta investigación permitió concluir que las formas de justificar las aserciones se vinculan con dos de las tres funciones que se han descrito para la atenuación: con la autoprotección para salvar la imagen propia y/o con la prevención de posibles daños a la imagen o problemas por invadir el territorio del otro. Así, la identidad del hablante se construye interactivamente. En particular, los actos de habla asertivos pueden ser escenarios conflictivos, de manera que la forma de manejar el conflicto interpersonal exigiría una alta preocupación por el yo y por el otro. Esto conlleva, a su vez, que la imagen se configure como un recurso de identidad que puede cambiar en el transcurso de la interacción.

Una investigación como la presentada contribuye indudablemente a los estudios pragmalingüísticos del español y, entre sus proyecciones, se halla por ejemplo la asociación de las estrategias para justificar con las variables sociales. Asimismo, este trabajo permitirá desarrollar investigaciones contrastivas con otras variedades del español, puesto que ya existe una propuesta para el habla de Monterrey (Flores y Ramírez 2015), a la que se suma esta, que describe el español chileno.

\section{Referencias bibliográficas}

Albelda, M. (2010). ¿Cómo se reconoce la atenuación? Una aproximación metodológica basada en el español peninsular hablado. En F. Orletti y L. Mariottini (Eds.), (Des)cortesía en español. Espacios teóricos y metodológicos para su estudio (pp. 41-70). Roma/Estocolmo: Università degli Studi Roma Tre/EDICE.

Albelda, M. (2016). Sobre la incidencia de la imagen en la atenuación pragmática. Revista Internacional de Lingüística Iberoamericana, 27(1), 19-32.

Albelda, M. (2018a). Variación sociolingüística de los mecanismos mitigadores: diferencias de uso en edad y sexo. Cultura, Lenguaje y Representación, 19, 7-29. https://doi.org/10.6035/ clr.2018.19.1

Albeda, M. (2018b). La variación genérico-discursiva de la atenuación como resultado de la variación de imagen. Spanish in Context, 15(2), 346-368. https://doi.org/10.1075/sic.00018.alb 
Albelda, M. (2018c). ¿Atenuación del compromiso del hablante?: el caso de los evidenciales por lo visto y se ve que. RILCE, Revista de Filología Hispánica 34(3), 1179-1214. Recuperado de https://dialnet.unirioja.es/servlet/articulo? codigo $=6651$ 498\&orden $=0$ \&info $=$ link

Albelda, M. y Álvarez, A. (2010). Los corpus discursivos en el estudio pragmático de la atenuación y de la intensificación. Revista Internacional de Lingüistica Iberoamericana, 8(2), 79-100. https://www.dx.doi.org/10.2307\%2F41678453

Albelda, M. y Cestero, A. M. (2011). De nuevo, sobre los procedimientos de atenuación lingüística. Español Actual: Revista de Español Vivo, 96, 121-155.

Albelda, M. y Mihatsch W. (2017). Atenuación e intensificación en géneros discursivos. Madrid/Frankfurt: Iberoamericana/Vervuert.

Albelda, M., Briz, A., Cestero, A. M., Kotwica, D., y Villalba, C. (2014). Ficha metodológica para el análisis pragmático de la atenuación en corpus discursivos del español (ES.POR.ATENUACIÓN). Oralia: Análisis del Discurso Oral, 17, 7-62.

Briz, A. (2001). El español coloquial en la conversación: esbozo de pragmagramática. Barcelona: Ariel.

Briz, A. (2002). La atenuación en una conversación polémica. En J. L. Blas Arroyo y otros (Eds.), Estudios sobre lengua y sociedad (pp. 87-103). Castelló: Universitat Jaume I, Servicio de Publicaciones.

Briz, A. (2003). La estrategia atenuadora en la conversación cotidiana española". En D. Bravo (Ed.), Actas del Primer Coloquio Internacional del Programa EDICE. La perspectiva no etnocentrista de la cortesía: identidad sociocultural de las comunidades hispanohablantes (pp. 17-46). Estocolmo: Universidad de Estocolmo.

Briz, A. (2004). Cortesía verbal codificada y cortesía verbal interpretada en la conversación. En D. Bravo y A. Briz (Eds.), Pragmática sociocultural: estudios sobre el discurso de cortesía en español (pp. 67-94). Barcelona: Ariel.

Briz, A. (2006). Atenuación y cortesía verbal en la conversación coloquial: su tratamiento en la clase de español como lengua extranjera. En Actas del Programa de Formación para profesorado de Español como Lengua Extranjera (pp. 227-255). Munich: Instituto Cervantes. 
Briz, A. (2007). Para un análisis semántico, pragmático y sociopragmático de la cortesía atenuadora en España y América. $L E A$ : Lingüística Española Actual, 29(1), 5-40.

Briz, A. (2012). La (no)atenuación y la (des)cortesía, lo lingüístico y lo social: ¿son pareja? En J. Escamilla y G. Henry (Eds.), Miradas multidisciplinares a los fenómenos de cortesía y descortesía en el mundo hispánico (pp. 33-75). Barranquilla: Universidad del Atlántico-Programa EDICE.

Briz, A. \& Estellés, M. (2010). On the relationship between attenuation, discourse particles and position. En G. Kaltenböck, W. Mihatsch, \& S. Schneider (Eds.), Studies in Pragmatics 9. New Approaches to Hedging (pp. 289-304). United Kingdom: Emerald Group Publishing

Briz, A y Albelda, M. (2013). Una propuesta teórica y metodológica para el análisis de la atenuación lingüística en español y portugués. La base de un proyecto en común (ES.POR. ATENUACIÓN). Onomázein, 27(2), 288-319. http://dx.doi. org/10.7764/onomazein.28.21

Briz, A., Pons, S., y Portolés, J. (Coords.). (2008). Diccionario de partículas discursivas del español. Recuperado de http://www.dpde.es

Cestero, A. M. (2012a). Recursos lingüísticos de atenuación en el habla de Madrid: estudio sociopragmático. En T. Jiménez, B. López, V. Vázquez, y A. Veiga (Coord.), Cum corde et in nova grammatica: estudios ofrecidos a Guillermo Rojo (pp. 233246). Universidad de Santiago de Compostela.

Cestero, A. M. (2012b). Estudio sociolingüístico de la atenuación en el corpus PRESEEA-Madrid. En A. Cestero, I. Molina, y F. Paredes (Eds.), La lengua, lugar de encuentro. Actas del XVI Congreso Internacional de la Asociación de Lingüistica y Filología de América Latina, Alfal (pp. 1897-1906). Alcalá de Henares: Servicio de Publicaciones de la Universidad de Alcalá.

Cestero, A. M. (2017). La atenuación en el habla de Madrid: patrones sociopragmáticos. RILCE: Revista de Filología Hispánica, 33(1), 57-86. https://doi.org/10.15581/008.33.1.57-86

Cestero, A. M. y Albelda, M. (2012). La atenuación lingüística como fenómeno variable. Oralia: Análisis del Discurso Oral, 15, 77-124.

Figueras, C. (2018). Atenuación, género discursivo e imagen. Spanish in Context, 15(2), 258-280. https://doi.org/10.1075/ sic.00014.fig 
Flores, E. y Ramírez, G. (2015). La atenuación de los actos asertivos: diferencias entre hombres y mujeres. Sociocultural Pragmatics, 3(1), 90-119. https://doi.org/10.1515/soprag-2014-0013

González Riffo, J. (2017). Estrategias de atenuación en narraciones de experiencia personal de hablantes de Santiago de Chile: un estudio sociopragmático (Tesis para optar al grado de Magíster en Lingüística). Universidad de Chile, Santiago de Chile.

González Riffo, J. (2019). Diminutivos atenuadores en narraciones de experiencia personal de hablantes de Santiago de Chile: ifenómeno variable? Cuadernos de Lingüística del Colegio de México, 6(1), 1-31. https://doi.org/10.24201/clecm.v6il.124

González Riffo, J. y Guerrero González, S. (2016). Estudio sociolingüístico del empleo de gradación de valoraciones inscritas en discursos argumentativos en el corpus PRESEEA de Santiago de Chile. Linred, Lingüistica en la red, 14. Recuperado de http://www.linred.es/articulos_pdf/LR-articulo-10102016. pdf

González Riffo, J. y Guerrero González, S. (2017). Estrategias de atenuación en narraciones conversacionales. Lengua y Habla, 21, 29-44. Recuperado de https://dialnet.unirioja.es/descarga/ articulo/6175060.pdf

González Riffo, J. y Guerrero González, S. (2018). Recursos de atenuación en la 'orientación' de narrativas personales orales desde una perspectiva sociopragmática. Nueva Revista del Pacífico, 68, 62-81. https://dx.doi.org/10.4067/S071951762018000100062

Guerrero, S. (en prensa). La atenuación lingüística en el corpus PRESEEA de Santiago de Chile. Alpha.

Kerbrat-Orecchioni, C. (1992). Les interactions verbales, II, París: Armand Colin.

Molina Martos, I. (2005). Estrategias de atenuación en el barrio de Salamanca de Madrid. Trabajo presentado en XIV Congreso Internacional de la Asociación de Lingüística y Filología de América Latina, Alfal. Memorias, vol. I, sección 'Dialectología y Sociolingüística'. Monterrey, Universidad Autónoma de Nuevo León.

Montecino, L. (2003). Cortesía y modalización en un foro de opinión en internet. Onomázein, 8, 73-98. Recuperado de http:// onomazein.letras.uc.cl/Articulos/8/5_Montecino.pdf 
Montecino, L. (2004). Intensificadores en el habla coloquial de jóvenes chilenos. Onomázein, 9, 9-32.

Puga, J. (1997). La atenuación en el castellano de Chile. Un enfoque pragmalingüistico. Valencia: Universidad de Valencia.

Rodríguez Alfano, L. (2018). La atenuación en justificaciones argumentativas en el corpus Monterrey-PRESEEA. Anuario de Letras. Lingüística y Filología, 6(1), 219-250. https://dialnet. unirioja.es/descarga/articulo/6818386.pdf

Rojas, D. (2008). Funciones actuales y evolución semántica de la locución de repente en el español de Chile. Boletín de Filología, 43(1), 207-237. Recuperado de https://boletinfilologia.uchile.cl/index.php/BDF/article/view/18051/18832

Samper, M. (2013). La atenuación lingüística en el español de Las Palmas de Gran Canaria. LEA: Lingüística Española Actual, 35(2), 181-204.

Samper, M. (2017). Análisis sociolingüístico de la atenuación en el español de Las Palmas de Gran Canaria. En M. Albelda y W. Mihatsch (Eds.). Atenuación e intensificación en géneros discursivos (pp. 153-168). Madrid/Frankfurt: Iberoamericana/ Vervuert.

Samper, M. (2018). Un cambio en tiempo real: la atenuación entre hablantes universitarios de Las Palmas de Gran Canaria. RILCE: Revista de Filología Hispánica, 34(3), 1259-1279. https:// doi.org/10.15581/008.34.3.1259-79

Schneider, S. (2013). La atenuación gramatical y léxica. Oralia: Análisis del Discurso Oral, 16, 335-356.

Schneider, S. (2017). Las dimensiones de la intensificación y de la atenuación. En M. Albelda y W. Mihatsch (Eds.), Atenuación e intensificación en géneros discursivos (pp. 23-42). Madrid/ Frankfurt: Iberoamericana/Vervuert.

Torres, Y. y Rodríguez, Y. (2016). La atenuación en Barranquilla: estudio sociopragmático. Cuadernos de Lingüistica Hispánica, 30, 55-79. https://doi.org/10.19053/0121053x.n30.0.6188

Villalba, C. (2018). Atenuación: algunas claves metodológicas para su análisis. Normas, 8(1), 306-316. Recuperado de https://ojs. uv.es/index.php/normas/article/view/13277/12565 